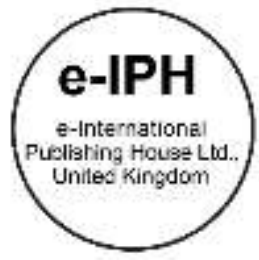

\title{
Restorative Effects of Open Spaces on the Physiological Health of Obese Adults in Saudi Arabia
}

\author{
Amr Mohamad Alabbasi1,2, Ismail Said² \\ ${ }^{1}$ Faculty of Islamic Architecture, College of Engineering and Islamic Architecture, \\ Umm Al Qura University, Makkah, Saudi Arabia. \\ 2 Department of Landscape Architecture, Faculty of Built Environment, \\ Universiti Teknologi, Malaysia, Johor Bahru, 81310, Malaysia \\ aalabbasia@gmail.com, ismailbinsaid@gmail.com \\ Tel: +966505635727,+601123295774
}

\begin{abstract}
It has been found that the restorative environment literature heavily focused on the relationship between experiencing open spaces and psychological health. Yet, the effect of open spaces on physiological health and well-being did not receive similar attention. This highlights the need for strategies that involve open spaces as a means to control the prevalence of obesity and improve the human physiological health and well-being. This study examines the restorative effects of open spaces on physiological health of obese adults in the city of Yanbu Alsenayah, which is a well-designed city in Saudi Arabia.
\end{abstract}

Keywords: Restorative environment; open spaces; obesity; physical activity.

eISSN: 2398-4287 @ 2018. The Authors. Published for AMER ABRA cE-Bs by e-International Publishing House, Ltd., UK. This is an open access article under the CC BYNC-ND license (http://creativecommons.org/licenses/by-nc-nd/4.0/). Peer-review under responsibility of AMER (Association of Malaysian Environment-Behaviour Researchers), ABRA (Association of Behavioural Researchers on Asians) and cE-Bs (Centre for Environment-Behaviour Studies), Faculty of Architecture, Planning \& Surveying, Universiti Teknologi MARA, Malaysia.

DOI: https://doi.org/10.21834/e-bpj.v3i8.1384

\subsection{Introduction}

It has been found that the restorative environment literature heavily focused on the relationship between experiencing open spaces and psychological health. Yet, the effect of open spaces on physiological health and wellbeing did not received similar attentions. In the 21 st century, many discoveries occurred about the obesity, one of the most significant was the link between the cardiovascular disease and weight loss. Countless studies suggested that the changes in the people live style affected their health and well-being. One of these studies concluded that many factors are substitute in the increase of the occurrence of obesity in the worldwide. Importantly, how the life style changed, which are allied with cumulative of urbanization, (Sicree \& Shaw, 2007).

\subsection{Problem Statement}

Many studies have led to the fact that encountering environment support has a restorative effect on visitors (Tsunetsugu et al, 2013; Cole and Hall, 2010; Staats and Hartig, 2004; Kaplan, 1992). Most of the studies that have been conducted aimed at measuring the outcomes of experiencing natural environment, such as reducing stress and restoration from attention fatigue. Most of these studies were concerned with the psychological health of adults and children. Also, it has been determined that patients with a good window view recover more rapidly than patients with bad or solid wall view (Ulrich 1984). Many studies have discussed the restorative environment and its effect on health. (Abraham, Sommerhalder, and Abel 2010).

eISSN: 2398-4287 @ 2018. The Authors. Published for AMER ABRA cE-Bs by e-International Publishing House, Ltd., UK. This is an open access article under the CC BYNC-ND license (http://creativecommons.org/licenses/by-nc-nd/4.0/). Peer-review under responsibility of AMER (Association of Malaysian Environment-Behaviour Researchers), ABRA (Association of Behavioural Researchers on Asians) and cE-Bs (Centre for Environment-Behaviour Studies), Faculty of Architecture, Planning \& Surveying, Universiti Teknologi MARA, Malaysia.

DOI: https://doi.org/10.21834/e-bpj.v3i8.1384 
There has been an increase in the number of studies that discussed the restorative effect of outdoor environment (Herzog, Maguire, and Nebel 2003; Maruani and Amit-Cohen 2007; Payne 2009; Tsunetsugu et al. 2013; Völker and Kistemann 2011a, 2011b). Most of these studies resulted in the development of Stress Recovery theory (Ulrich, 1984), which was then followed by Attention Fatigue theory (Kaplan \& Kaplan 1989). The potential restorative influence of landscape open spaces affect mental health (psychological health) by separating the city residents from their daily life, and physical health (physiological health) by promoting physical activities (Abraham, Sommerhalder, and Abel 2010).

In Sweden, for sustainable development, good health has become the most important resource (Stigsdotter, 2005). As a result, health issues are a serious problem to be studied these days. One of the most serious problems in the 21 th century is obesity and its related diseases. Obesity related diseases are conditions which arise as consequences of obesity such as diabetes, high blood pressure, and cardiovascular diseases (WHO 2016). According to The World Health Organization (WHO), adults over 17 years old who are considered obese reached 600 million in 2014. Generally, 13\% of the world's population was obese in 2014 (WHO 2016). According to WHO, obesity is the accumulation of an abnormal amount of fat, and it is measured by body mass index (BMI), which is the weight in kilos divided by height in meter2 (WHO 2016). Obesity leads to many diseases such as cardiovascular diseases and type two diabetes (T2D) (WHO 2016).

In the 21st century, many discoveries have been made about obesity. One of the most significant was the link between obesity related disease and weight loss (Sicree and Shaw 2007). Losing weight helps in preventing the occurrence of obesity which in turn prevents its related diseases. According to the authors, losing weight could control the glucose level in the blood and could help to cure T2D. In urban environment, people are have less mobility in their daily life than ever before. It has been suggested that the changes in peoples' live style has affected their health and well-being. The new urban life style depends on vehicles for transportation, and the consumption of junk food, in addition to being physically inactive. It is concluded that many factors were responsible for the increased occurrence of diabetes worldwide. These factors are the reduction of physical activity, and the increased in rates of obesity. More importantly, change in life style has been allied with the growth of urbanization (Sicree and Shaw, 2007). Most of the health problems and chronic diseases found in people living in Arab towns, such as diabetes, high blood pressure, and high cholesterol, can be attributed to bad urban planning, which has led to a change in the lifestyle of the population, such as dependence on vehicles for transportation and the consumption of junk food (Alsayed, 2010). The lifestyle of the people these days has become more dependent on machines, and people are more physically inactive. Thus, what physical activities can help people to lose weight? Exercising, walking, jogging and swimming are activities that can help in losing weight.

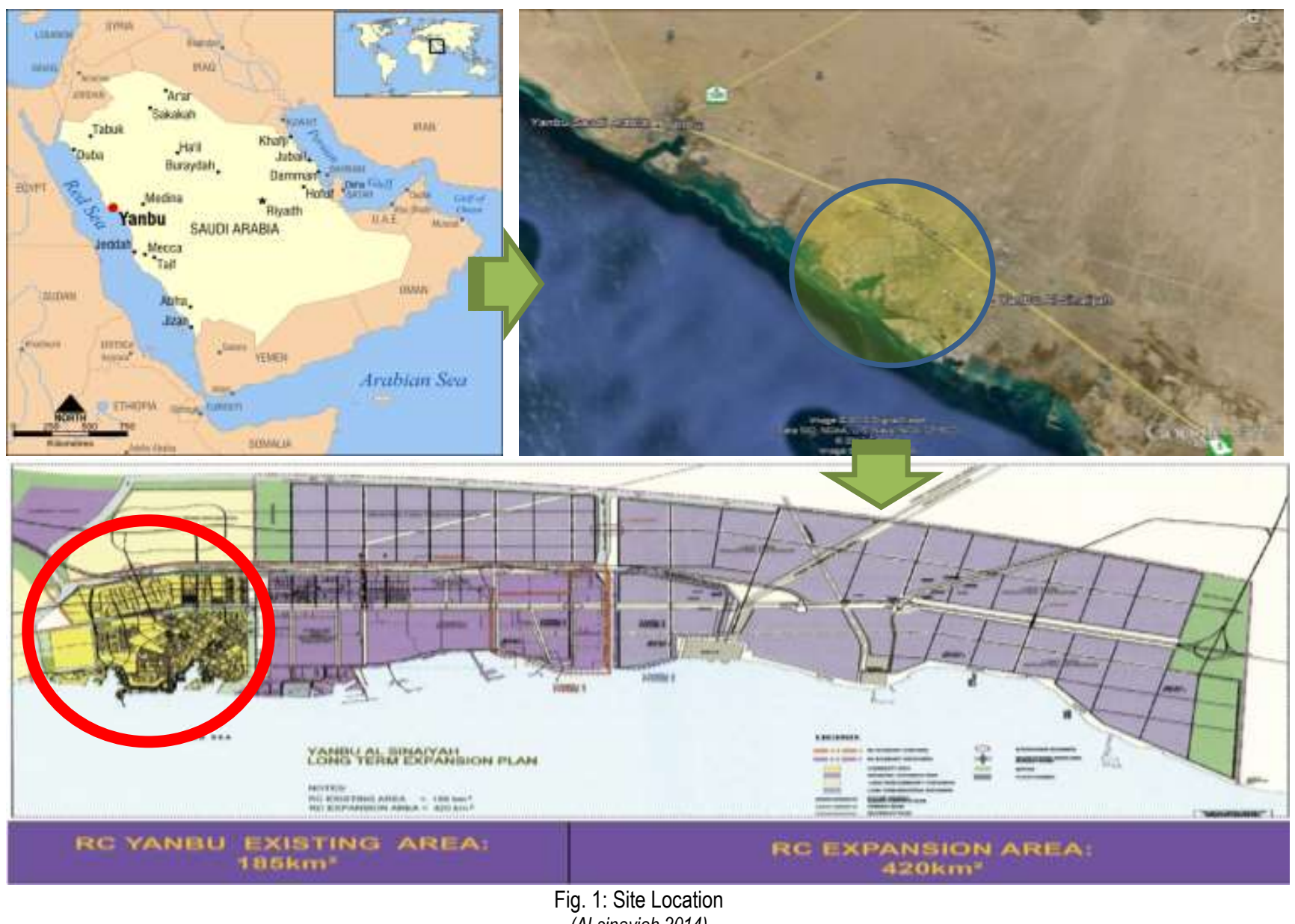


According to WHO, by 2025 the number of people diagnosed with type 2 diabetes will reach 200-300 million (Hussain et al. 2007). Hypertension (raised blood pressure)i and type 2 diabetes occur more frequently in obese adults than in lean people at almost every age. Weight loss is effective in reducing obesity and its related diseases (Thakur, Reisin, and Richards 2001). Since obesity is an increase in body weight, which means an increase in body mass index BMI (WHO 2016), losing weight is the first step to stop obesity and prevent its related diseases. Type 2 diabetes risk (which is considered one of the obesity diseases) is linked roughly to two factors; environmental exposure and genetics (Hussain et al. 2007). How is environmental exposure related to T2D? It is suggested that sedentary lifestyle plays an important role in obesity prevalence. Environmental exposure means visiting urban parks and outdoor open spaces, thereby could encouraging people to be physically active. For example, exercising, jogging, walking, and swimming. All of these activities could occur in Yanbu open spaces. Overweight happens more often because of an inactive life style. In addition, physical inactivity has been identified as a risk factor of obesity and its related disease, which are Type 2 diabetes, high blood pressure, and cardiovascular diseases (Hussain et al. 2007). As a result, physical inactivity lead to obesity, which has affected people around the world. Therefore, to be physically active means being more healthy. According to WHO, all body movement performed by muscles requires the expenditure of energy; for example, walking, cycling, or participating in sports is usually defined as physical activity(WHO 2016). This can occur at open spaces in urban areas. In Yanbu, the open spaces that provide space for physical activity are waterfront and nieghorhood parks. Physical activity for adult on a regular daily basis could reduce the risk of type 2 diabetes by 20-60 percent (Hussain et al. 2007). Moreover, most of the prevention programs for type 2 diabetes require that people change their lifestyle. Thus, inserting physical activity in daily schedule of the people who live in urban context, espacially obese adults, could prevent the obesity and its consequences. This indicates how beneficial physical activity like exercising helps in losing weight and preventing T2D. In 2010, adults (aged 20-79) diagnosed with type 2 diabetes numbered 285 million and will increase to 439 million by 2030, globally (Shaw, Sicree, and Zimmet 2010). This study will find the relation between physical activity performed by obese adults and reduction of obesity in certain types of open spaces. The study will be held in Saudi Arabia at one of the well-planned cities along the coast of the Red Sea. This city, which is known in Arabic as Mdinat Yanbu Asenayah(MYAS), is the industrial city of Yanbu. It is located 350 kilometers northwest of Jeddah in Al Madinah province of western Saudi Arabia (see maps below). Industrial Yanbu is a major Red Sea port and was established in 1977 and it is still under development. It was designed and planned by Parsons Cooperation and is currently managed by the Royal Commission of Jubail and Yanbu (Al-But'hie and Eben Saleh 2002).

MYAS community area occupies 5,587 ha, 1450 ha of the community is subdivided into twenty three districts which can accommodate 96,000 people (Al-sinayiah 2014). Moreover, the length of the waterfront of the city is eleven kilometers ,the smallest width is $20 \mathrm{~m}$ and the longest width is $250 \mathrm{~m}$, and its area is 420 ha. The community has twenty five different parks spread within the city.

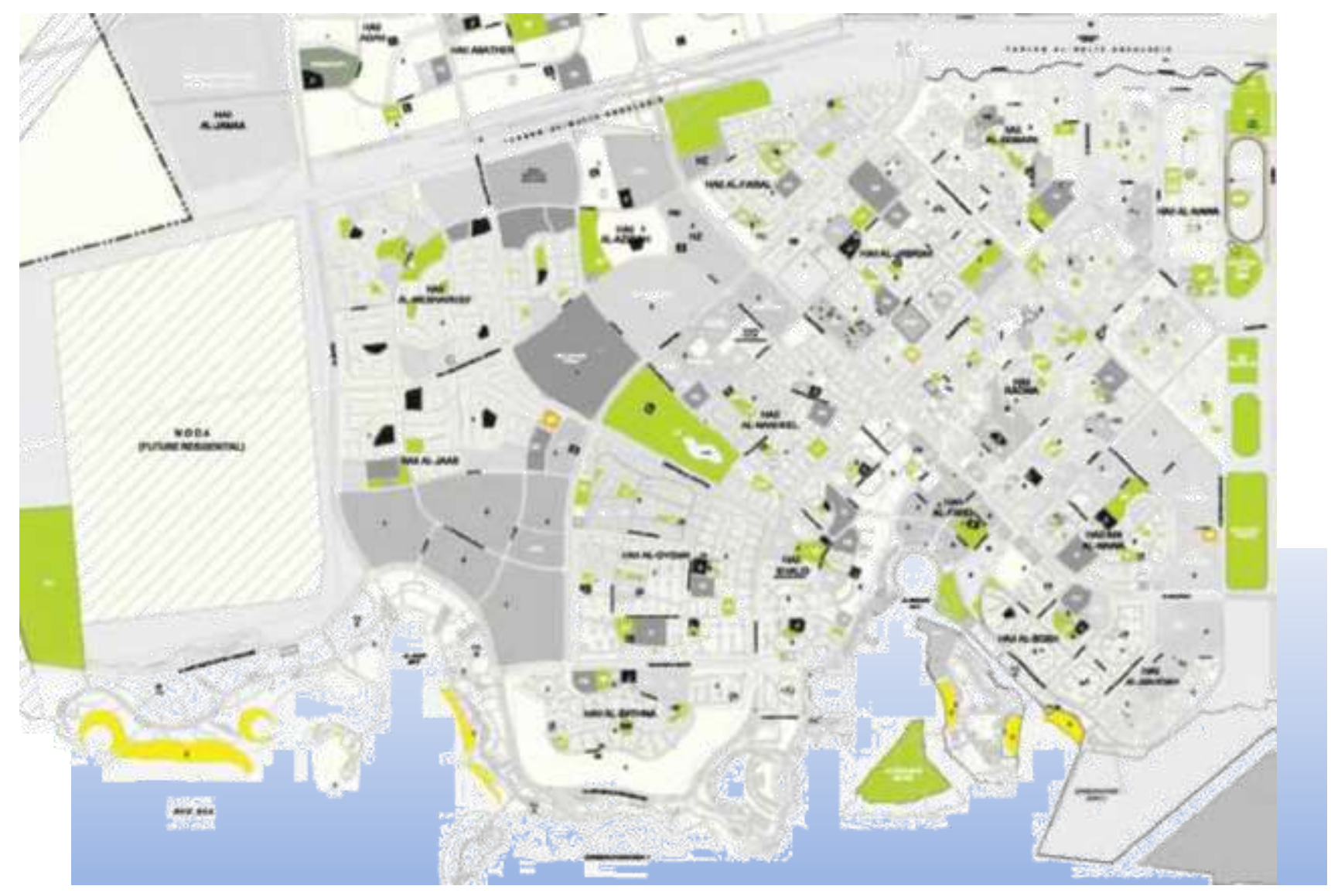

Fig. 2: Site Location 
There is potential relationship between transport behaviors and obesity (Brown et al. 2017). Since people are using vehicles and public transportation, they are likely less physically active, which it is happening in Yanbu. Positive effects on health occurred because of physical activities users experience at waterfront parks. These physical activities like jogging, swimming, and exercising are known to prevent cardiovascular illnesses and obesity (Völker and Kistemann 2011b). It is proven that outdoor physical activity causes more positive mood and attitude than indoors (Sandifer, Sutton-Grier, and Ward 2015). Thus, what makes exercising outdoors more attractive than indoors? And what make outdoor space more attractive than others? It has been shown that spaces along water are preferred by the users to spend leisure time and engage in recreational activities, and to receive restoration from the daily stresses (Völker and Kistemann 2013). This study will prove the relation between the prevalence of obesity among obese adults in Saudi Arabia and the availability of urban open spaces. One of the identified ways that link landscape and physical health wellbeing is promoting physical activity in everyday life and leisure time by providing a walkable environment (Abraham, Sommerhalder, and Abel 2010). In MYAS, the most of the urban open spaces in MAYS are equipped with walkways (Al-sinayiah 2014).

\subsection{Literature Review}

Urban parks are defined as open space areas reserved for public, and mostly dominated by vegetation and water (Konijnendijk et al. 2013). In MYAS, waterfront parks and neighborhood parks are the open space provided by The Royal Commission for Jubail and Yanbu (RCJY). Possibly, engagement in physical activities in both parks can reduce stress (Tyrväinen et al. 2014) and obesity. This can lead to reducing the risk of diabetes, high blood pressure, and cardiovascular disease. Studies discussing obesity and its related disease interaction with physical activity were conducted by four different disciplines including medical (AR Al-Nuaimt, K Al-Rubeaanl, Y AlMazrou2, O Al-Attasl, 1996), environmental psychology (Parsons, 1991), urban design, landscape architecture (Frank et al., 2004), and community design (Frank et al., 2004).

In 2014, 600 million adults 18 years and older were obese around the world (WHO 2016). This show how serious this health issue has become. What are the reasons behind this phenomenon? It has been suggested that the new life style such as sedentary lifestyle and eating junk food are behind the obesity prevalence (AR Al-Nuaimt, K Al-Rubeaanl, Y Al-Mazrou2, O Al-Attasl 1996; WHO 2016; Dubbert et al., 2002). Obesity has other effects that consequentially occur with its appearance. These effects, which are called obesity related disease (Hu 2013), include diseases such as type 2 diabetes (T2D), hypertension or high blood pressure, cardiovascular diseases (WHO 2016). However, many medical studies analyzed the obesity problem to stop its rapid spread. These studies suggested preventive strategies that can stop obesity and its related diseases. Two main strategies are improving physical activity as daily routine and fixing the daily diet (Hussain et al. 2007; Pais 2006). This study focus on improving physical activity.

On the other hand, urban design and landscape architecture studies suggested that open space promotes more physical activeness (Giles-Corti \& Donovan 2002). Since this study is examining the restorative effect of open spaces, it is necessary to show how previous study presented the relation between physical activity and obesity and its related diseases.

In medical terms, obesity is the increasing of body mass index because of gaining weight (WHO 2016). Consequently, losing weight is the logical reaction. But what about the obesity related diseases? How does physical activity affect diabetes, high blood pressure, and cardiovascular disease? Medical studies discussed the benefit of routine physical activity on the obesity related diseases. These physical activities such as walking, jogging and exercising can be done in open space in MYAS.

Type 2 diabetes is one of the obesity related diseases, and globally it has become one of the most prevalent diseases (Hu 2013). Diabetes has two types, and the focus of this study is type 2. Type 2 diabetes is defined as the condition when the body cannot use the insulin hormone efficiently, which causes the increasing of the glucose concentration level in the blood (WHO 2016). The glucose level in the blood should be less than $100 \mathrm{mg} / \mathrm{dl}$ for normal person, $100-125 \mathrm{mg} / \mathrm{dl}$ is considered prediabetes, and $126 \mathrm{mg} / \mathrm{dl}$ or higher is considered diabetes (American Diabetes Association 2016). Thus, to measure the effect of physical activity on diabetic person, the glucose level should be monitored.

Saudi Arabia was ranked sixth in diabetes prevalence in 2011(Whiting et al., 2011). This can show the seriousness of this problem of diabetes as well as obesity in Saudi Arabia. It has been suggested that to prevent T2D, lifestyle must be changed by becoming more physically active, and changing the daily diet (Hussain et al. 2007), which could happen at open spaces such as neighborhood parks and waterfront parks. Thus, being physically active affects diabetes and this is the restorative effect the study is going to measure. As a result, physical activity affects obesity in two different ways, losing weight and controlling one of the related diseases, which is T2D. Losing seven percent of the body weight and moderate exercising for 30 minutes five days a week could reduce the risk of T2D by 58 percent (American Diabetes Association 2016). Therefore, the commitment of keeping physically active on a daily basis gives an image of how crucial physical activity is for urban people. Another study also suggested that $150 \mathrm{~min} /$ week of leisure-time physical activity, which is considered moderate, reduced the risk of diabetes by 36 percent (Smith et al. 2016). This could help to show how beneficial physical activity is in the reduction of diabetes and obesity. However, another study suggests that high intensity physical activity helps to control the glucose level in the blood in T2D diagnosed people (Peter Adams, 2013). This raises the question, "how is moderate, high or low intensity exercise determined? There are two different methods to measure physical activity intensity, subjective and objective. First, the subjective methods to draw an assessment about the intensity using questionnaires and diaries (Strath et al. 2013). It is possible that these two ways may not be accurate for this study, because the time frame is short and the data will be self-reported. The objective method, in contrast, has many categories, namely: Measuring the expenditure of energy: it is measuring the calorimetry or 
how many calories has been used during this activity Motion sensors: this method counts how many steps have been taken, which then determines the distance covered. Physiological measures: such as heart rate monitoring (Strath et al. 2013). According to the American Heart Association, exercise is considered moderate if the heart rate reached 50-69 percent of the person's maximum heart rate, and high if it reached 70-89 percent (American Heart Association 2016) as shown in the table below.

Table1: Heart beat zones according to age

\begin{tabular}{lll}
\hline Age & Target HR zone $50-85 \%$ & Max heart rate \\
\hline 20 & $100-170$ & 200 \\
30 & $95-162$ & 190 \\
40 & $90-153$ & 180 \\
50 & $85-145$ & 170 \\
60 & $80-136$ & 160 \\
70 & $75-128$ & 150 \\
\hline
\end{tabular}

Combined assessment method: a combination of more than one of the previous categories (Strath et al. 2013). This method is more suitable for this study because the collected data will be more accurate since it is more automated. It depends on different type of gadgets that count the heart rate and energy amount that determine the intensity of the physical activity. There are gadgets which combine two or three assessment methods that could be used in the study. In previous studies, gadgets such as accelerometer and pedometer were used to measure motion (Strath et al. 2013). Smart watches such as Apple watch could measure average heart rat, calories, and distance and this could be used in data collection. It is obvious from the previous studies how much physical activity is beneficial to the obese adults who were diagnosed with T2D. Furthermore, it shows how the intensity of the physical activity plays a role in how it is effective in controlling diabetes. The second obesity related disease is hypertension or high blood pressure. Hypertension is the condition that occurs when the blood pressure continuously rises, causing increased stress on the vessels (WHO 2015b). Blood level readings are important to understand, to figure out what is considered high and what is not (see the table) (American Heart Association 2017).

Table 2: Blood pressure values

\begin{tabular}{lll}
\hline Top number (systolic) in $\mathrm{mm} \mathrm{Hg}$ & Bottom number (diastolic) in $\mathrm{mm} \mathrm{Hg}$ & The category \\
\hline Below 120 & Below 80 & Normal blood pressure \\
Between $120-139$ & Between $80-89$ & Prehypertension \\
Between $140-159$ & Between $90-99$ & Stage 1 \\
160 or higher & 100 or higher & Stage 2 \\
\hline
\end{tabular}

(American Heart Association 2017)

It is shown that high blood pressure is more prevalent among obese and overweight people than normal people (Papathanasiou et al. 2014). Many studies have examined the relation between physical activity and blood pressure. In older women, habitual physical activity is associated with decrease of blood pressure (Reaven et al. 1991). Does this effect apply to men as well? Another study which has been conducted in Cameroon concluded that obesity, diabetes, and hypertension are more prevalent in urban areas than rural areas, and it is affected by physical activity, however it is not significant for women (Sobngwi et al. 2002). Another study suggested that the intensity of the physical activity plays a role in controlling hypertension (Paffenbarger et al. 1983). Possibly, the intensity of the physical activity is what made this opposing argument and this could be solved by this study if the intensity has been measured. Another study raised disagreement, suggesting that blood pressure is only associated with BMI, not with smoking or with physical activity status (Papathanasiou et al. 2014). Thus, there are different sides to this issue, but what all sides agreed on is the relation between blood pressure and obesity. As a result, reducing obesity helps in preventing hypertension, which is considered a restorative because of being physically active in outdoor spaces. In Yanbu, 20 percent of the residential area are green spaces (Al-sinayiah 2014) and because Yanbu is a well-designed city, this study will be conducted there.

The third obesity related disease is cardiovascular disease (CVD). It is a condition that affects heart and blood vessels including the failure of delivering blood to the body parts such as brain and heart muscle (WHO 2015a). This disease is the result of being obese, which leads to increased glucose level in the blood and unstable blood pressure (American Diabetes Association 2016; Whiting et al. 2011). Thus, cardiovascular diseases occur as the result of obesity, and the other two related diseases increase the risk of it occurring. As a result, preventing obesity causes a reduction of $\mathrm{T} 2 \mathrm{D}$ and $\mathrm{BP}$, consequentially reducing the risk of CVD.

In sum, habitual moderate physical activity causes a reduction in the prevalence of obesity. Thus, it will cause to prevent the occurrence of type 2 diabetes, high blood pressure, and cardiovascular diseases.

As discussed in medical field, the ultimate goal is the enhancing of physical activity of obese people. What are the keywords within the environmental psychology to achieve this goal? It is suggested that people who live in cities along water have attachment to the spaces along water (Völker \& Kistemann 2013). As a result, spaces along water attract the people to spend their leisure time at water fronts. Thus, waterfront parks have the potential to be a restorative environment for obese adults. In addition, there are many possible physical activities a user could do while they are experiencing the spaces at the waterfronts such as jogging, swimming and workingout (Völker \& Kistemann 2011b; Doherty et al. 2014). It has been found by another study that people who live close to the coast are usually physically more active (Giles-Corti \& Donovan 2002). In sum, it can be assumed that availability of waterfronts in cities has a restorative effect on the residents. Thus, the preference for outdoor space can encourage people to use it in their leisure time. Yanbu is 
a well-planned coastal city and from the author's experience, the people use the waterfront parks for recreation. The author was working as landscape operation and maintenance section manager in MYAS, responsible for the landscaping O\&M at the residential area. Another study suggested that the quality of the open space increases the time people spend there for walking (Ekkel \& de Vries 2017). Furthermore, outdoor spaces could help people to be more physically active, which sometimes depends on design, mentality, andlor the distance (Herzog et al. 2003; Giles-Corti \& Donovan 2002). Thus, how attractive the park is plays a role in encouraging people to engage. Since Yanbu is following standards in designing open space, the possibly of quality parks in Yanbu is good because it is welldesigned city. However, the obese adults opinion, which will be collected in this study, will clarify which space is more preferred, waterfronts parks or neighborhood parks and why. As result, the preference and attractiveness are the factors that control the eagerness of obese adults to be more physically active at outdoor parks. These two factors will help to show which space is helping the obese adults to be more active, which means more restorative effect from the outdoor spaces. In this study, the restorative effect is controlling glucose level in the blood, lowering blood pressure and losing weight.

In landscape architecture, urban design and community design, obesity has been discussed in relation with the built environment. The scale which has been discussed varied in every study. For example, in community design, every hour of using vehicle per day increases the risk of the obesity by 6 percent (Frank et al. 2004). Thus, new life style that depends on vehicle for transportation is increasing the possibility of obesity, which is happening in MYAS (Zawawi 2013). The design has the influence to promote physical activity in daily life and leisure time by enhancing the walkability of the environment (Abraham et al., 2010). Walkability is the most often mentioned word because it has effect on peoples' health. For each kilometer of walking, the obesity risk reduced by 4.8 percent (Frank et al., 2004). This raises the question, "why don't people walk?" Another study suggested that the land use design plays a role, the accessibility to open spaces improving peoples' health (Sandifer et al. 2015). In MYAS, there are 14 square kilometer of green open spaces (Al-sinayiah 2014). Thus, the amount of green open spaces provide good accessibility for the residents for physical activity. Therefore, in landscape architecture scale, the availability of open spaces system in Yanbu could encourage people to walk more. Other aspects also discussed included well-designed landscape spaces attracting people (Abraham et al. 2010), and that helps people to be more active by providing walkways, pedestrian zone and cycling tracks. MYAS was designed and planned by an American cooperation with expertise in this area, which is Parsons Cooperation (Zawawi 2013). This cooperation is still working as consultant with RCJY until present time. MYAS has received the third place prize in the Arab Cities Organization landscaping competition in 2013 (Al-sinayiah, 2014). As a result, Yanbu is a well-designed city and has high quality green open spaces.

The most important keywords in the community design, landscape architecture and urban design are walkability and reducing the use of vehicles. Another study contradicts this idea by suggesting that there is no relation between park use and physical activity (Zenk et al., 2011). Therefore, this contradiction could be solved through this study in the context of Yanbu. Accessing landscape open spaces is important for health, but more evidence is needed (Ward Thompson, 2011). This states that there are a gap in the evidence which can be provided by this study. Studies about urban parks showed that people who spend time in parks are usually more physically active. For example, being in urban park encouraged people to walk, play social games and do other physical activities (Völker \& Kistemann, 2011b; Ahern, 1991; Völker \& Kistemann, 2011a; Doherty et al., 2014; Abraham et al., 2010). Moreover, to do some passive activities such as bird watching, fishing, and sitting have good physiological, psychological, and social benefits. In MYAS, people do some of these activities such as walking, jogging, fishing, and sitting at the waterfront, which called in Arabic Cornich.

In sum, because of the availability of open spaces system in Yanbu, people especially the obese adults, can engage in physical and passive activities at outdoor spaces.

\subsection{Methodology}

\subsection{Research design}

The aim of this study is to examine the restorative effects of the urban open spaces in well-designed cities. This may show the link between the quality of the open spaces and the health quality of the residents of Saudi Arabia. Therefore, it will investigate the physical activeness of the users while they are at urban open spaces (independent variable) towards the physiological health (dependent variable). The data in this study obtained through by Physical check-up: it builds the quantitative data that can help in distinguishing the relationship of experiencing urban open spaces with the physiological health and well-being. The targeted measurements are blood sugar, blood pressure, and heart beat rate. This measurements helps to link the physical activities to the health and well-being of the obese adults. Professional help needed in this stage. The author went to one of the public hospitals to take a short course in taking the readings of glucose level in the blood and blood pressure and its principles.

The study will compare the collected data from two urban spaces in a well-planned city in Saudi Arabia. This city is Madinat Yanbu Alsenayah (MYAS). The first space is the waterfront of MYAS, and the second space is a neighborhood park in the city. These two spaces have same design theme, which is curvilinear walkway that could be used for exercising.

Research Methods

This research will involve the preparation of an experimental study. Experimental study is to look over the possible factors that could cause or influence a specific condition or phenomenon (Leedy \& Ormrod, 2013). It means that this study will examine the influence of being physically active at outdoor spaces on obese adults by measuring the change in the glucose level in the blood and the blood pressure. This research focused on the obese adult resident's experience of the current open spaces in MYAS. The parameters that will be measured in this study are (1) blood pressure (BP), (2) blood glucose level (BG), (3) heart beat rate (HB), This data set will show the relation between experiencing urban open spaces and the obesity prevalence. 
The spaces which will be used for collecting the data at MYAS have been chosen for the following reasons:

Both of the spaces are linear parks

Both have walkway systems which could be used for exercising

Designed and approved by RCYJ and has services.

Both of the sites are accessible by car if they live one kilometer away from the park and by walking if they live less than one kilometer. In addition, the two sites are located in two different sides of the city (see the map). As a result, if an obese adult lives in the middle of the city, they have the same chance to use any of the two sites.

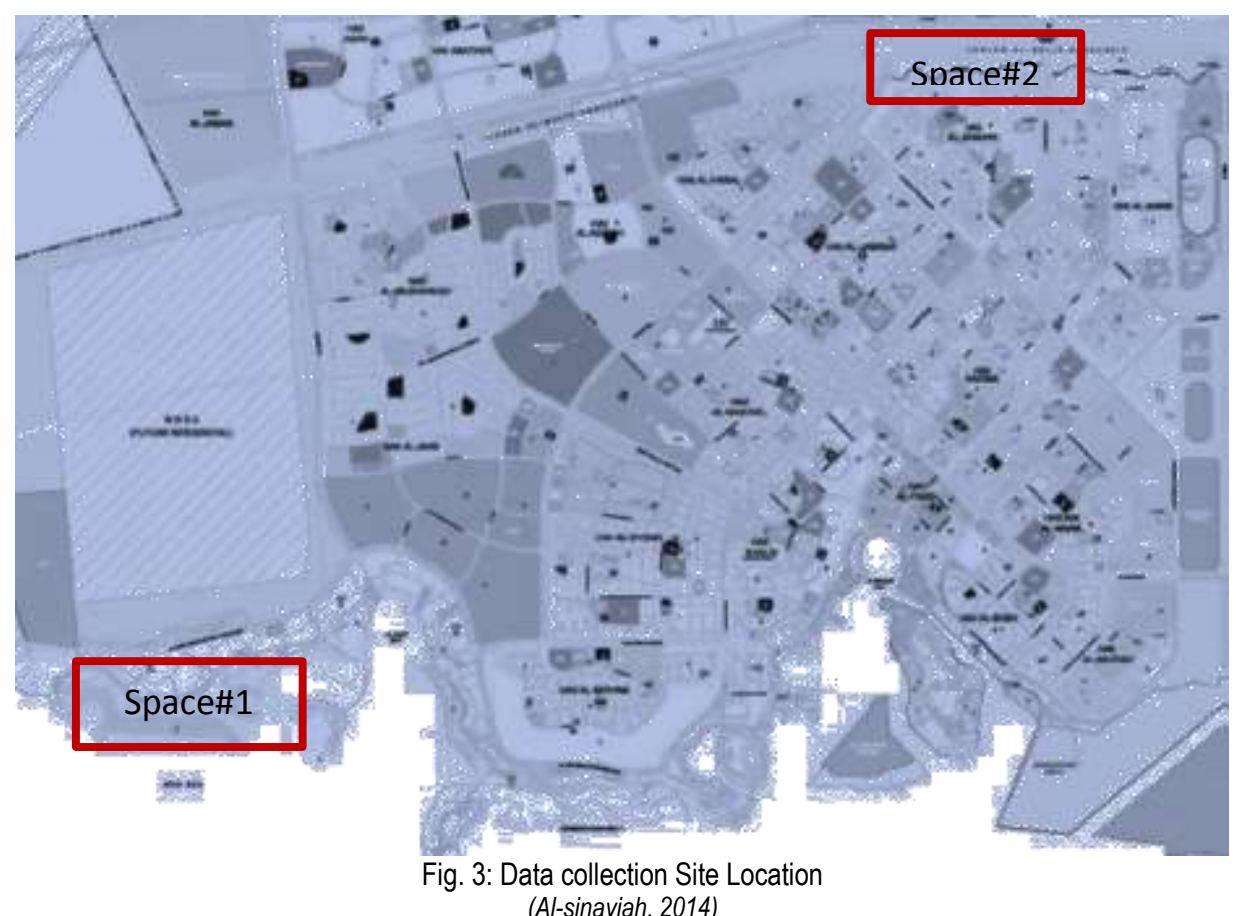

The test procedure is to advise each group to gather at chosen space, either the Waterfront Park or Neighborhood Park, and they should eat two hours prior to the test time. Then, all the measurements will be taken at the site on the before and after the exercise each day for five days. The measurements that has been taken are BP, BG, and HB.

Next, the subjects will start experiencing the chosen space for one hour. According to the previous studies, moderate physical activity for 30 minutes per day is minimum (Smith et al., 2016; Zethelius et al., 2014). However, due to the author's experience as a type 2 diabetic patient, 40-60 minutes is beneficial to control the glucose level. This single hour will be called the test stage. During the test stage, the participant was observed by wearing smart watch which recorded the participants' average heart rate, energy expenditure, where were they during this hour by GPS and step count. They will receive a short massage via SMS to inform them that the time is up. Then, the subjects will gather at one spot, where they will be provided with water and rest for 15 minutes. The three variables will then be measured again. This stage will be called post-test stage. This procedure will be repeated for five days in each park to monitor the gradual results, and to investigate if there any differences between the spaces in terms of commitment. The researcher has recruited a 38 participants. Each site had 19 participants for five days.

\subsection{Discussion}

\subsection{Data Analysis}

The data will be analyzed in two different ways. The glucose differences will be tested by using the T-test for the mean of the different before and after the exercise. On the other hand, the blood pressure will be tested by how often do the respondents' blood pressure improved after the workout.

\subsubsection{Glucose Level}

t-Test: Paired Two Sample for Means

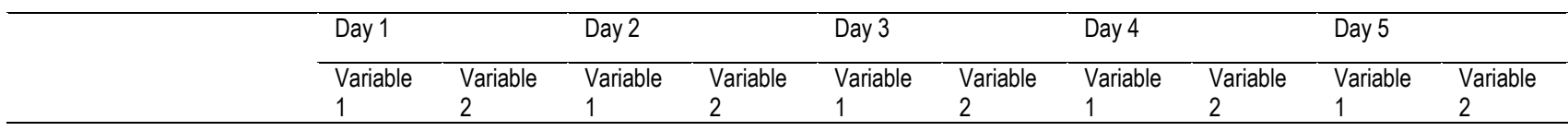




\begin{tabular}{|c|c|c|c|c|c|c|c|c|c|c|}
\hline Mean & 158.3636 & 134.7614 & 157.7102 & 134.3068 & 157.0625 & 133.8409 & 156.4375 & 133.4545 & 155.8239 & 133.0852 \\
\hline Variance & 4093.616 & 3407.12 & 4090.378 & 3403.037 & 4090.882 & 3409.666 & 4094.339 & 3416.386 & 4098.203 & 3427.358 \\
\hline Observations & 176 & 176 & 176 & 176 & 176 & 176 & 176 & 176 & 176 & 176 \\
\hline Pearson Correlation & 0.979919 & & 0.979806 & & 0.980075 & & 0.980436 & & 0.981146 & \\
\hline $\begin{array}{l}\text { Hypothesized Mean } \\
\text { Difference }\end{array}$ & 0 & & 0 & & 0 & & 0 & & 0 & \\
\hline DF & 175 & & 175 & & 175 & & 175 & & 175 & \\
\hline t Stat & 23.2435 & & 22.99695 & & 22.97294 & & 22.91796 & & 23.04982 & \\
\hline P-value (one-tail) & $1.09 \mathrm{E}-55$ & & $4.48 \mathrm{E}-55$ & & $5.14 \mathrm{E}-55$ & & $7.04 \mathrm{E}-55$ & & $3.31 \mathrm{E}-55$ & \\
\hline t Critical one-tail & 1.653607 & & 1.653607 & & 1.653607 & & 1.653607 & & 1.653607 & \\
\hline
\end{tabular}

\subsubsection{Blood Pressure}

\begin{tabular}{lllll}
\hline & Subjects number & Showed improvement & Did not show improvement & percentage \\
\hline Day 1 & 38 & 19 & 19 & $50 \%$ \\
\hline Day 2 & 38 & 18 & 20 & $47 \%$ \\
\hline Day 3 & 38 & 20 & 18 & $52 \%$ \\
\hline Day 4 & 38 & 20 & 18 & $52 \%$ \\
\hline Day 5 & 38 & 20 & 18 & $52 \%$ \\
\hline
\end{tabular}

\subsection{Data interruption}

The exercise significantly reduced the glucose level each day. Since, the P. value one tail is less than $0.05 \mathrm{H} 0$ should be rejected upon examining the mean before and after exercise it is clearly shown that before mean is greater than the after mean indicating that there is significant reduction in the glucose level in the blood after the exercise.

Besides, above $50 \%$ of the respondents showed improvement in the blood pressure readings after the same exercise which indicate that the engagement in physical activity at open spaces benefited the respondent in improving their readings of the blood pressure and glucose level.

\subsection{Conclusion}

In conclusion, this experimental study has looked over the relation between experiencing an urban open space and the physiological health of the users. The data collected by taking the readings of the glucose level and the blood pressure of the 38 obese respondents in two different urban open space in MYAS in Saudi Arabia. After analyzing the data it shows that experiencing the open spaces has a physiological benefit not only a psychological. The drop in the glucose level of the subjects and the improvement of the blood pressure proved that benefit. Besides, it provide another benefit which is decreasing the prevalence of obesity and its related diseases. The properties of the open spaces at Yanbu Alsenayah motivate the users to be physically active which improve the weight loss and help to control the glucose level in the blood and the blood pressure.

\section{References}

Abraham, A., Sommerhalder, K. \& Abel, T., 2010. Landscape and well-being: a scoping study on the health-promoting impact of outdoor environments. International journal of public health, 55(1), pp.59-69

Al-But'hie, I. \& Eben Saleh, M., 2002. Urban and industrial development planning as an approach for Saudi Arabia: the case study of Jubail and Yanbu. Habitat International, 26(1), pp.1-20. Available at: http://www.sciencedirect.com/science/article/pii/S0197397501000261.

Al-sinayiah, Y., 2014. Yanbu Al-Sinayiah, American Diabetes Association, 2016. Diagnosing Diabetes and Learning About Prediabetes A1C Fasting Plasma Glucose ( FPG ) Oral Glucose Tolerance Test ( also called the OGTT ). , pp.5-8.

American Heart Association, 2016. Target Heart Rates - AHA. Available at: http://www.heart.org/HEARTORG/GettingHealthy/PhysicalActivity/FitnessBasics/TargetHeart-Rates_UCM_434341_Article.jsp [Accessed May 12, 2017].

American Heart Association, 2017. What Do Blood Pressure Numbers Mean? American Heart Association, pp.3-5. Available at: http://www.heart.org/HEARTORG/Conditions/HighBloodPressure/KnowYourNumbers/Understanding-Blood-Pressure-

Readings_UCM_301764_Article.jsp\#.WRiKueWGPIU [Accessed October 5, 2017].

AR Al-Nuaimt, K Al-Rubeaanl, Y Al-Mazrou2, O Al-Attasl, N.A.-D. and T.K., 1996. high prevel obesity.pdf. Available at: https://www.researchgate.net/profile/Yagob_AlMazrou/publication/14419582_High_Prevalence_of_overweight_and_obesity_in_Saudi_Arabia/links/Odeec5309b7f827d68000000/High-Prevalence-of-overweight-andobesity-in-Saudi-Arabia.pdf.

Brown, V. et al., 2017. Active transport and obesity prevention - A transportation sector obesity impact scoping review and assessment for Melbourne, Australia. Preventive Medicine, 96, pp.49-66. Available at: http://dx.doi.org/10.1016/j.ypmed.2016.12.020. 
Creswell, J.W., 2003. Research design Qualitative quantitative and mixed methods approaches. Research design Qualitative quantitative and mixed methods approaches, pp.3-26.

Dubbert, P.M. et al., 2002. Obesity, Physical Inactivity, and Risk for Cardiovascular Disease. The American Journal of the Medical Sciences, 324(3), pp.116-126.

Ekkel, E.D. \& de Vries, S., 2017. Nearby green space and human health: Evaluating accessibility metrics. Landscape and Urban Planning, 157, pp.214-220. Available at: http://dx.doi.org/10.1016/j.landurbplan.2016.06.008.

Frank, L.D., Andresen, M.A. \& Schmid, T.L., 2004. Obesity relationships with community design, physical activity, and time spent in cars. American Journal of Preventive Medicine, 27(2), pp.87-96.

Giles-Corti, B. \& Donovan, R.J., 2002. The relative influence of individual, social and physical environment determinants of physical activity. Social Science \& Medicine, 54(12), pp.1793-1812.

Herzog, T.R., Maguire, C.P. \& Nebel, M.B., 2003. Assessing the restorative components of environments. Journal of Environmental Psychology, 23(2), pp.159-170.

Hu, F.B., 2013. Resolved: There is sufficient scientific evidence that decreasing sugar-sweetened beverage consumption will reduce the prevalence of obesity and obesityrelated diseases. Obesity Reviews, 14(8), pp.606-619.

Hussain, A. et al., 2007. Prevention of type 2 diabetes: A review. Diabetes Research and Clinical Practice, 76(3), pp.317-326.

Konijnendijk, C.C. et al., 2013. Benefits of Urban Parks - A systematic review. International Federation of Parks and Recreation Administration, (January), pp.1-68. Leedy, P.D. \& Ormrod, J.E., 2013. Practical Research: Planning and Design,

Maruani, T. \& Amit-Cohen, I., 2007. Open space planning models: A review of approaches and methods. Landscape and Urban Planning, 81(1-2), pp.1-13. Available at: http://www.sciencedirect.com/science/article/pii/S0169204607000199 [Accessed February 11, 2017].

Paffenbarger, R.S. et al., 1983. Physical activity and incidence of hypertension in college alumni. American journal of epidemiology, 117(3), pp.245-57. Available at: http://www.ncbi.nlm.nih.gov/pubmed/6829553.

Pais, P., 2006. Preventing ishaemic heart disease in developing countries,

Papathanasiou, G. et al., 2014. Association of High Blood Pressure with Body Mass Index, Smoking and Physical Activity in Healthy Young Adults. The Open Cardiovascular Medicine Journal, pp.5-17.

Parsons, R., 1991. The potential influences of environmental perception on human health. Journal of Environmental Psychology, 11(1), pp.1-23. Available at: http://www.sciencedirect.com/science/article/pii/S0272494405800027 [Accessed January 25, 2017].

Payne, S., 2009. Open Space: People Space. Journal of Environmental Psychology, 29(4), pp.532-533. Available at: http://linkinghub.elsevier.com/retrieve/pii/S0272494409000814.

Peter Adams, O., 2013. The impact of brief high-intensity exercise on blood glucose levels. Diabetes, Metabolic Syndrome and Obesity: Targets and Therapy, 6, pp.113122

Reaven, P.D., Barrett-Connor, E. \& Edelstein, S., 1991. Relation between leisure-time physical activity and blood pressure in older women. Circulation, 83(2), pp.559565

Sandifer, P.A., Sutton-Grier, A.E. \& Ward, B.P., 2015. Exploring connections among nature, biodiversity, ecosystem services, and human health and well-being: Opportunities to enhance health and biodiversity conservation. Ecosystem Services, 12, pp.1-15. Available at: http://www.sciencedirect.com/science/article/pii/S2212041614001648 [Accessed February 15, 2017].

Shaw, J.E., Sicree, R.A. \& Zimmet, P.Z., 2010. Global estimates of the prevalence of diabetes for 2010 and 2030. Diabetes Research and Clinical Practice, 87(1), pp.414.

Smith, A.D. et al., 2016. Physical activity and incident type 2 diabetes mellitus: a systematic review and dose???response meta-analysis of prospective cohort studies. Diabetologia, pp.1-19. Available at: http://dx.doi.org/10.1007/s00125-016-4079-0.

Sobngwi, E. et al., 2002. Physical activity and its relationship with obesity, hypertension and diabetes in urban and rural Cameroon. International Journal of Obesity, 26(7), pp.1009-1016. Available at: http://www.nature.com/doifinder/10.1038/sj.jjo.0802008.

Strath, S.J. et al., 2013. Guide to the assessment of physical activity: Clinical and research applications: A scientific statement from the American Heart association. Circulation, 128(20), pp.2259-2279.

Thakur, V., Reisin, E. \& Richards, R., 2001. Obesity, Hypertension, and the Heart. The American Journal of the Medical Sciences, 321(4), pp.242-248. Available at: http://www.sciencedirect.com/science/article/pii/S0002962915346735 [Accessed April 14, 2017].

Tsunetsugu, Y. et al., 2013. Physiological and psychological effects of viewing urban forest landscapes assessed by multiple measurements. Landscape and Urban Planning, 113, pp.90-93. Available at: http://dx.doi.org/10.1016/j.landurbplan.2013.01.014.

Tyrväinen, L. et al., 2014. The influence of urban green environments on stress relief measures: A field experiment. Journal of Environmental Psychology, 38, pp.1-9. Available at: http://www.sciencedirect.com/science/article/pii/S0272494413000959 [Accessed January 25, 2017].

Völker, S. \& Kistemann, T., 2011a. International Journal of Hygiene and The impact of blue space on human health and well-being - Salutogenetic health effects of inland surface waters : A review. , 214, pp.449-460. 
Völker, S. \& Kistemann, T., 2013. Social Science \& Medicine "I' m always entirely happy when I' $m$ here ! " Urban blue enhancing human health and well-being in Cologne and Düsseldorf, Germany. Social Science \& Medicine, 78, pp.113-124. Available at: http://dx.doi.org/10.1016/j.socscimed.2012.09.047.

Völker, S. \& Kistemann, T., 2011b. The impact of blue space on human health and well-being â€“" Salutogenetic health effects of inland surface waters: A review. International Journal of Hygiene and Environmental Health, 214, pp.449-460.

Ward Thompson, C., 2011. Linking landscape and health: The recurring theme. Landscape and Urban Planning, 99(3-4), pp.187-195. Available at: http://www.sciencedirect.com/science/article/pii/S0169204610002860 [Accessed October 19, 2016]

Whiting, D.R. et al., 2011. IDF Diabetes Atlas: Global estimates of the prevalence of diabetes for 2011 and 2030. Diabetes Research and Clinical Practice, 94(3), pp.311321. Available at: http://dx.doi.org/10.1016/j.diabres.2011.10.029.

WHO, 2015a. Media centre - Cardiovascular Diseases (CVDs). fact sheet N. 317, (January), p.[Online]. Available at: http://www.who.int/mediacentre/factsheets/fs317/en/. WHO, 2016. Obesity Related Abstracts. world health organization. Available at: http://www.who.int/mediacentre/factsheets/fs311/en/.

WHO, 2015b. WHO | Q\&As on hypertension. world health organization. Available at: http://www.who.int/features/qa/82/en/ [Accessed April 17, 2017].

Zawawi, A., 2013. Post occupancy evaluation of industrial yanbu, saudi arabia: residents' perceptions after 35 years of operation. Cnarnav UNtvBRsrry.

Zenk, S.N. et al., 2011. Activity space environment and dietary and physical activity behaviors: A pilot study. Health and Place, 17(5), pp.1150-1161. Available at: http://dx.doi.org/10.1016/j.healthplace.2011.05.001.

Zethelius, B. et al., 2014. Level of physical activity associated with risk of cardiovascular diseases and mortality in patients with type-2 diabetes: report from the Swedish National Diabetes Register. European journal of preventive cardiology, 21(2), pp.244-51. Available at: http://www.ncbi.nlm.nih.gov/pubmed/24227183. 